\title{
Seguimiento fotogramétrico de exhalaciones del volcán Popocatépetl, en México, durante el año 2016
}

\author{
Photogrammetric follow-up of the Popocatepetl volcano exhalations, \\ in Mexico, during the year 2016
}

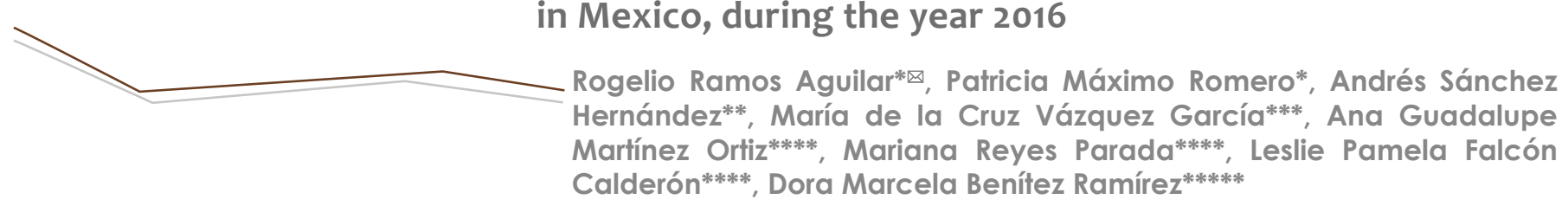

Ramos Aguilar, R., Máximo Romero, P., Sánchez Hernández, A., Vázquez García, M. C., Martínez Ortiz, A. G., Reyes Parada, M., Falcón Calderón, L. P., \& Benítez Ramírez, D. M. (2018). Seguimiento fotogramétrico de exhalaciones del volcán Popocatépetl, en México, durante el año 2016. Investigación y Ciencia de la Universidad Autónoma de Aguascalientes, 26(73), 37-48.

\section{RESUMEN}

En el siguiente trabajo se muestra un estudio sobre la reciente actividad del volcán Popocatépetl, analizando imágenes de las columnas eruptivas del mismo y apoyados en herramientas de fotogrametría terrestre y satelital para su clasificación; se calculó la emanación de gases, cenizas, altura y dirección.

Después de 67 años, el día 21 de diciembre de 1994 el volcán tuvo actividad eruptiva. Las columnas alcanzaron $3 \mathrm{~km}$ de altitud aproximadamente, aumentó la emisión de ceniza y los sismómetros indicaban tremores del movimiento del magma en la estructura.

Palabras clave: volcán; Popocatépetl; cráter; fotogrametría.

Keywords: volcano; Popocatepetl; crater; photogrammetry.

Recibido: 22 de mayo de 2017, aceptado: 13 de noviembre de 2017

* Facultad de Ingeniería, Benemérita Universidad Autónoma de Puebla. Av. San Claudio y 18 Sur, C. P. 72570, C. U., Puebla, Puebla, México. Correo electrónico: rogelio.ramos@correo.buap.mx; patricia.maximo@correo.buap.mx

** Facultad de Arquitectura, Benemérita Universidad Autónoma de Puebla. Av. San Claudio y 18 Sur, C. P. 72570, C. U., Puebla, Puebla, México. Correo electrónico: andres.sanchez@correo.buap.mx

*** Bufete de Ingeniería en Telecomunicaciones y Sistemas. José Toribio Medina 130, C. P. 06880, Algarín, Ciudad de México, México. Correo electrónico: mayanegui@gpo-bits.com.mx

**** Colegios de Ingeniería Topográfica y Geodésica y Mecánica y Eléctrica, Benemérita Universidad Autónoma de Puebla. Av. San Claudio y 18 Sur, C. P. 72570, C. U., Puebla, Puebla, México. Correo electrónico: ana.martinezo@alumno.buap.mx; mariana.reyesp@alumno.buap.mx; leslie.falcon@alumno.buap.mx

***** Universidad de Boyacá campus Tunja. Carrera 2a Este 64-169, Tunja, Colombia. Correo electrónico: dmbenitez@uniboyaca.edu.co
Este acontecimiento marcó la reactivación del volcán; en este estudio se muestra un análisis fotogramétrico de la superficie y perímetro del cráter para determinar las deformaciones que ha sufrido hasta 2016 generadas por la actividad volcánica; para este estudio se recurrió a imágenes satelitales y aplicación de software especializado para su procesamiento.

\section{ABSTRACT}

The following work shows a study about the recent activity of the Popocatepetl volcano, analyzing images of the eruptive columns of the same and supported by terrestrial and satellite photogrammetry tools for their classification; the emanation of gases, ashes, height and direction were calculated.

After 67 years, on December 21, 1994 the volcano had an eruptive activity. The columns reached up to $3 \mathrm{~km}$ altitude, the ash emission increased and the seismometers indicated tremors of the movement of the magma in the structure.

This event marked the reactivation of the volcano, this study shows an analysis of the surface and perimeter of the crater, to determine the deformations that it has suffered until 2016 generated by the activity that the volcano has experienced; for this study, satellite images and application of specialized software for its processing were used.

\section{INTRODUCCIÓN}

Entre las estructuras volcánicas que se encuentran en México, el volcán Popocatépetl se ubica como uno 
IIVESTIGACIÓn Y CIERCIA DE LA UNIVERSIDAD AUTÓNOMA de los de mayor interés, basándose en su actividad sísmica y eruptiva reciente. Se localiza en los límites de los estados de Puebla, México y Morelos en el centro del Cinturón Volcánico Mexicano (CVM),

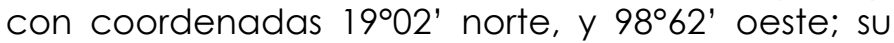
forma lo clasifica como un estratovolcán.

A lo largo de su historia, el volcán ha sufrido modificaciones, según Demant (1978) se podría dividir en dos fases; la primera se caracteriza por la formación y posterior destrucción de dos edificios volcánicos: Nexpayantla y El Fraile. El primero destruido por una erupción ocurrida aproximadamente hace 200,000 años.

En su lugar, se formó una caldera volcánica denominada El Fraile, originada por una depresión de vertientes andesíticos y dacíticos. Sin embargo, esta geoforma sufrió un colapso hace 30,000 años aproximadamente, provocando una erupción y destruyendo el lado sur del mismo. (Macías, 2005, p. 396)

Posteriormente, registró erupciones plinianas que formaron el cono actual, seguido por periodos de actividad intensa con erupciones explosivas, la última de este tipo en el año 800 d.C. Existen registros prehispánicos de actividad fumarólica entre los años 1363 y 1512 (figura 1). "En el año 1519, Hernán Cortés relata sobre una emisión de ceniza y el historiador Bernal Díaz redactó sobre una erupción ocurrida ese mismo año y en 1539, sobre una emisión de ceniza" (Macías, 2005, p. 395).

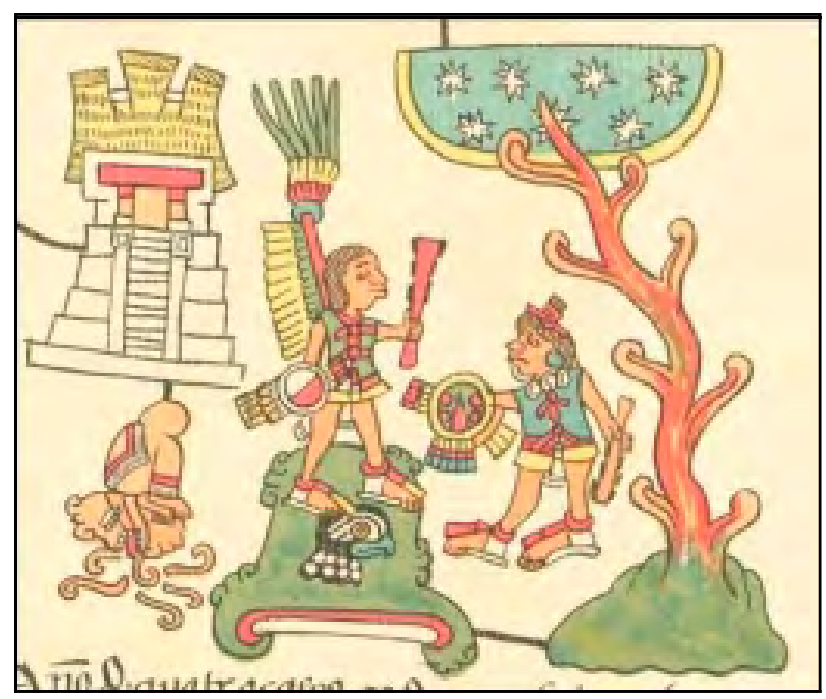

Figura 1. Erupción del Popocatépetl en 1509. Códice Telleriano Remensis (Espinasa-Pereña, 2014).
Dicha actividad se prolongó hasta el año 1593, en 1642 se registran emisiones de ceniza y actividad fumarólica. De 1663 a 1697 el volcán experimentaría una erupción de mediana intensidad, con flujos de lava andesítica (De la Cruz, 1997).

En 1927 ocurrió una fuerte erupción, con expulsión de material piroclástico que ocasionó la formación de un domo de lava en el fondo del cráter. En 1993 incrementó su actividad con fumarolas y sismicidad. "En octubre de 1994, se registró un pico de energía sísmica" (Espinasa-Pereña \& Martín-Del Pozzo, 2006, p. 102).

En marzo de 1996 nuevamente se registran emisiones de ceniza e índices importantes de sismicidad que apuntaban a movimiento de magma de forma gradual; se identifica un cuerpo creciente de lava en el interior del cráter y el 30 de abril de ese año sufre una exhalación explosiva. "La expulsión provoca lluvia de ceniza en las comunidades vecinas como Xalitzintla y San Nicolás de los Ranchos y los piroclastos son lanzados a distancias considerables en las inmediaciones del volcán" (Espinasa-Pereña \& Martín-Del Pozzo, 2006, p. 119).

Un evento explosivo con altas columnas de ceniza y fragmentos de pómez ocurrió el 30 de junio de 1997 entre las 18:11 y las 19:26 (tiempo local). En pocos minutos la columna eruptiva alcanzó 13 $\mathrm{km}$ de altura, un evento explosivo con columnas de ceniza y en las siguientes horas se reportaron lluvias de ceniza en estados vecinos como México e inclusive Cuernavaca; el material sólido fue lanzado en un radio de $10 \mathrm{~km}$ con una concentración importante al norte de la estructura, en su mayoría fragmentos de pómez de hasta $10 \mathrm{~cm}$ y también fueron expulsadas rocas de varios decímetros en los flancos del volcán. El cuerpo de lava descubierto en 1996 fue destruido en su mayoría por esta explosión, pero el 4 de julio se pudo apreciar que un nuevo cuerpo de lava comenzaba a aparecer sobre los restos del anterior.

De 1997 a 2000, estudios del CENAPRED (2012) revelaron la formación de cuatro domos que fueron destruidos por actividad explosiva en el último mes del 2000 y por lo cual 40,000 habitantes fueron evacuados, ya que fragmentos de rocas salieron como proyectiles a $5 \mathrm{~km}$ del cráter y la actividad volcánica aumentaba. El volumen de lava que se acumuló en el interior del cráter se estimaba entre 15 y 19 millones de metros cúbicos y presentaba un crecimiento 
importante con respecto al tiempo transcurrido. "A mediados de diciembre, tuvieron lugar tres erupciones de mediana intensidad, con columnas de ceniza moderadas y material incandescente lanzado a pocos kilómetros del cráter" (Espinasa-Pereña \& Martín-Del Pozzo, 2006, p. 102).

En enero de 2001 se presentaron exhalaciones de vapor de agua seguidas por flujos piroclásticos de ceniza que entraron en contacto con el glaciar El Fraile, generó un lahar que descendió aproximadamente $15 \mathrm{~km}$. Desde ese año hasta el $2011 \mathrm{cre-}$ cieron y se destruyeron 35 domos; el año 2011 empezaría con expulsión de material incandescente emitido hasta aproximadamente 500 metros en el flanco este del volcán.

Desde el mes de febrero hasta septiembre de 2001 hubo diariamente 100 exhalaciones de baja intensidad, posteriormente disminuyeron y se aceleraron con eventos sísmicos de baja magnitud para así dar lugar a la formación del domo 34 que habría sido destruido en noviembre de ese año por una explosión donde el volcán emitió roca basáltica y columnas de ceniza que alcanzaron los $2 \mathrm{~km}$, se observaron fumarolas en las laderas externas que indicaban una sobrepresión; el sistema de detección de anomalías térmicas (MODVOLC) de la Universidad de Hawái (HIGP, s. f.) localizó puntos calientes en el cráter del volcán, lo cual se asoció con un emplazamiento del domo que el 9 de diciembre llegaría a su fin con una explosión de material incandescente. Los tremores duraron hasta el 18 del mismo mes y una semana después el Sistema MODVOLC apagó la alarma, lo que indica el fin de ese proceso eruptivo.

A partir del año 2012 su actividad ha sido continua por esa razón. El objetivo de este trabajo es analizar la modificación del perímetro del cráter por la actividad del volcán, para ello se empleará la fotogrametría, que permite obtener medidas fidedignas a partir de fotografías aéreas que reúnen requisitos prefijados, con el objeto de determinar características métricas tales como tamaño, forma y posición, como también producir una representación precisa del objeto fotografiado enfocándose en la medición de exhalaciones mediante el Sistema de Información Geográfica (SIG) que fue diseñado para almacenar, capturar, analizar y manipular la información referenciada geográficamente y como herramienta auxiliar se utilizará una cámara.

\section{MATERIALES Y MÉTODOS}

Para el análisis y el seguimiento fumarólico se utilizaron técnicas fotogramétricas terrestres y satelitales, una cámara activa las $24 \mathrm{~h}$ del día permite la vigilancia visual que consiste en observar las manifestaciones físicas del volcán, tales como derrumbes o deslaves, deformaciones, fumarolas, emisiones de ceniza y gases 0 cualquier otra que indique cambios perceptibles. Para realizar este monitoreo se instaló una cámara de video en Calpan (CBTA 255), la cual envía directamente información para la generación de una base de datos para el análisis estadístico. Para el análisis del cráter se aplicaron sistemas de información geográfica de última generación. Además se contó con información documentada de CENAPRED y se emplearon herramientas libres de la Universidad de Hawái y de distintos sitios web como el United States Geological Survey (USGS, s. f.) y el EARTHQUAKE8.

\section{Análisis de la actividad fumarólica}

El estudio de las fumarolas se realizó gracias a la instalación de una cámara de monitorización que tiene su estación principal en el municipio de Calpan, Puebla $\left(19.06^{\circ} \mathrm{N}, 98.27^{\circ} \mathrm{O}\right)$. Se trata de un circuito cerrado que proporciona la imagen en tiempo real del volcán Popocatépetl, medio por el cual se hace constante vigilancia y permite la obtención de fotografías para su estudio. La distancia entre donde se encuentra instalada la cámara y el volcán es de 21.1 kilómetros, según la medición con la herramienta de Google Earth. El análisis que se muestra a continuación se llevó a cabo entre agosto y diciembre de 2016.

Se aplicó técnica fotogramétrica para medición de fumarolas, se estableció un factor de escala variable, ya que el tamaño de las imágenes proporcionadas por la cámara en ocasiones no era constante (movimiento) debido a fenómenos meteorológicos. Como referencia para sacar el factor de escala se tomó la altura del volcán (5426 m.s.n.m.), a partir de ese dato se determinó la altura de las fumarolas registradas en el lapso previamente señalado. Sin embargo, es importante señalar que existe un rango de incertidumbre en las mediciones debido a la capacidad panorámica de la cámara, que en caso de fumarolas de gran tamaño como las que se exponen más adelante resulta con un faltante de aproximadamente 2,000 metros. Para lograr el análisis de manera precisa, estos datos fueron cotejados con los expuestos por el CENAPRED. 


\section{Metodología empleada para el año 2012}

Mediante el programa ArcGis y con la imagen LANDSAT obtenida de la plataforma USGS se comenzó el proceso con la georreferencia de la imagen, se aplicó el datum WGS84 y se creó así un nuevo archivo SHAPE, con la característica de polígono, se le asignó un nombre de referencia. Con la herramienta de Editar se delimitó el cráter para crear un polígono que permitió al programa analizar la información contenida en la imagen y así poder obtener los datos necesarios como perímetro y área (figura 2).

\section{Metodología empleada para el año 2013}

El proceso para el análisis fue el mismo que se explicó anteriormente. La imagen de satélite rapideye fue obtenida de la plataforma PLANET (s. f.) y se referenció al datum WGS84. Posteriormente se trazó un polígono delimitando el cráter

\section{Metodología empleada para el año 2014}

En este proceso se utilizaron imágenes LANDSAT, fue obtenida de la plataforma USGS, y en las figuras que se muestran a continuación se puede observar que se llevó a cabo el mismo procedimiento que en los anteriores análisis.

\section{Metodología empleada para el año 2015}

Se utilizaron imágenes rapideye de la plataforma PLANET y las figuras que se muestran a continuación describen el procedimiento que se llevó a cabo, que es idéntico al descrito en los años anteriores.

\section{Metodología empleada para el año 2016}

Por último, la imagen de este año fue obtenida por la plataforma PLANET y analizada de la misma manera que las anteriores, como se puede observar en las siguientes imágenes.

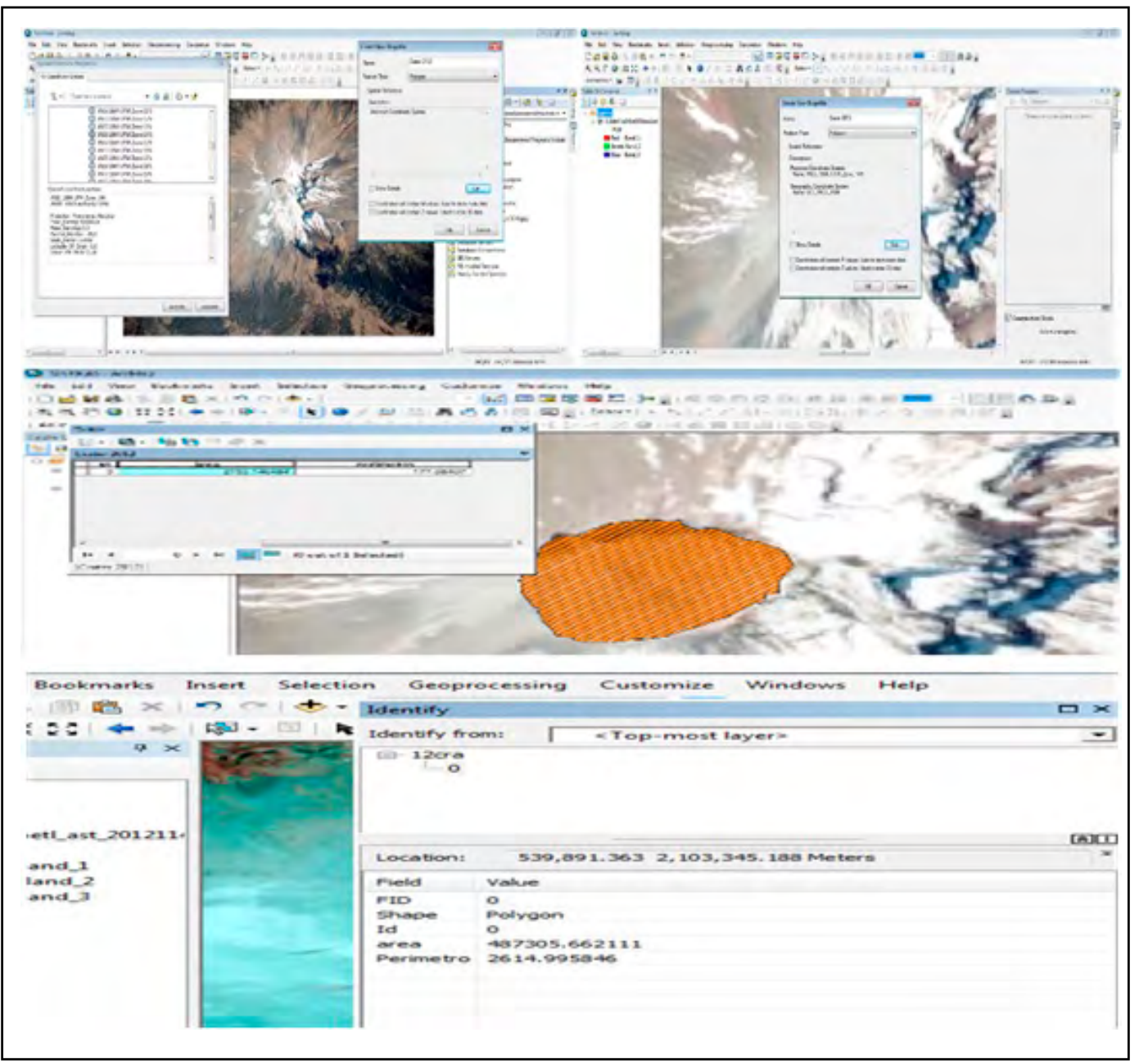

Figura 2. Proceso para obtener el perímetro y área del cráter y determinar las deformaciones de los últimos años. Elaboración propia. 
Tabla 1

Tabulación de datos recabados con el estudio de las imágenes

\begin{tabular}{|c|c|c|c|c|}
\hline Fecha & Hora & Altura (m) & Tipo de fumarola & Orientación \\
\hline $09 / 14 / 2016$ & $02: 27: 37$ & 1716,91 & Vapor de agua & Noreste \\
\hline $09 / 23 / 2016$ & $07: 01: 33$ & 1961,91 & Vapor de agua & Noreste \\
\hline $09 / 23 / 2016$ & $07: 50: 20$ & 1356,77 & Vapor de agua & Noreste \\
\hline $09 / 23 / 2016$ & $07: 50: 59$ & 1428,77 & Vapor de agua & Noreste \\
\hline $09 / 23 / 2016$ & $08: 35: 41$ & 1096,36 & Vapor de agua & Noreste \\
\hline $09 / 23 / 2016$ & $08: 50: 28$ & 1298,32 & Vapor de agua & Noreste \\
\hline $10 / 10 / 2016$ & $08: 14: 52$ & 1693,45 & Vapor de agua & Norte \\
\hline $10 / 10 / 2016$ & 08:23:10 & 1492,53 & Vapor de agua & Norte \\
\hline $10 / 10 / 2016$ & $09: 05: 26$ & 2927,66 & Vapor de agua & Norte \\
\hline $10 / 10 / 2016$ & 10:23:04 & 1291,61 & Vapor de agua & Noreste \\
\hline $10 / 11 / 2016$ & $05: 05: 47$ & - & Incandescencia & - \\
\hline $10 / 11 / 2016$ & $07: 15: 23$ & 1090,70 & Vapor de agua & Norte \\
\hline $10 / 11 / 2016$ & 09:03:24 & 1865,67 & Vapor de agua & Norte \\
\hline $10 / 13 / 2016$ & $05: 19: 43$ & - & Incandescencia & - \\
\hline $10 / 23 / 2016$ & 04:26:04 & - & Incandescencia & - \\
\hline $10 / 23 / 2016$ & $05: 45: 33$ & - & Incandescencia & - \\
\hline $10 / 23 / 2016$ & 08:03:35 & 3572,46 & Vapor de agua & Norte \\
\hline $10 / 23 / 2016$ & $08: 55: 57$ & 2904,44 & Vapor de agua & Norte \\
\hline $10 / 23 / 2016$ & $09: 17: 24$ & 2671,56 & Vapor de agua & Norte \\
\hline $10 / 23 / 2016$ & $10: 49: 37$ & 2672,09 & Vapor de agua & Norte \\
\hline $10 / 23 / 2016$ & $10: 59: 25$ & 2933,49 & Vapor de agua & Norte \\
\hline $10 / 23 / 2016$ & $11: 06: 43$ & 1423,18 & Vapor de agua & Noreste \\
\hline $10 / 24 / 2017$ & $07: 47: 48$ & - & Vapor de agua & Noreste \\
\hline $10 / 25 / 2017$ & $05: 05: 45$ & - & Incandescencia & - \\
\hline
\end{tabular}

Nota: Elaboración propia.

\section{RESULTADOS}

\section{Base de datos}

En la tabla 1 se presenta la base de datos con la fecha, hora, altura en metros, tipo de fumarola observada (vapor de agua, ceniza, incandescencia) y dirección de la fumarola con respecto a la dirección del viento.

Bimestre: agosto-septiembre. Este periodo de exhalaciones comenzó el 25 de agosto, cuando el volcán emitió columnas de ceniza que rápidamente se dirigieron al noreste por la dirección de los vientos y la baja intensidad de la fumarola. Desde las 7:10 h hasta las 8:07 h (figura 3) aproximadamente, la columna observada que obtuvo una altura inicial

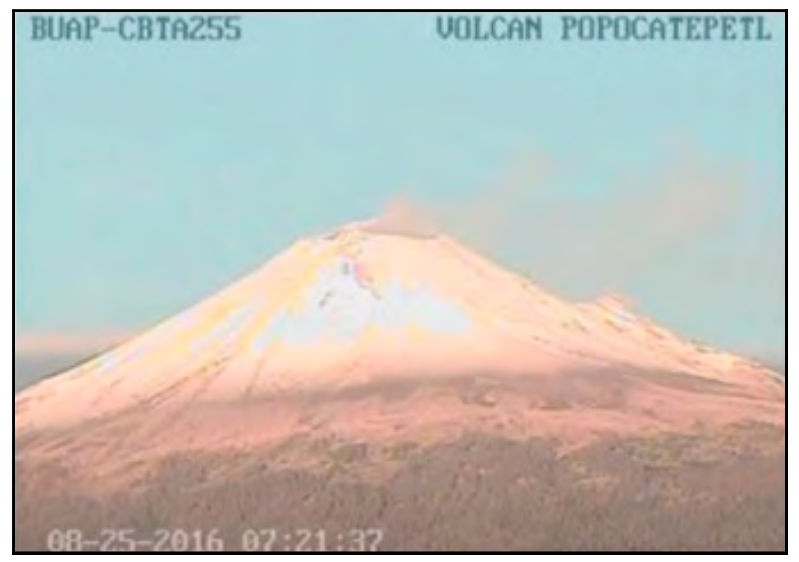

Figura 3. Exhalación de ceniza ocurrida el 25 de agosto con una altura de $1,273 \mathrm{~m}$.

Elaboración propia. 
IIVESTIGACIÓn Y CIERCIA DE LA UNIVERSIDAD AUTÓNOMH

42

\section{DE AGUASCALIERTES}

de 1,583 m se disipó con una mediana rapidez hasta los 1,273 m, lo que llevó a suponer que la actividad fumarólica había concluido. Esto fue desmentido una hora después, cuando el volcán experimentó una exhalación de vapor de agua que se elevó a los 1,432 m con la misma dirección.

Después de esto la actividad disminuyó hasta las 18:08 h (figura 4), después hubo una fumarola de ceniza que emergió a la superficie con una presión considerable ya que a pesar de los vientos que se dirigían al noreste, la columna se levantó con una altitud de 3,509 m hacia el norte, para después y a medida que la actividad volvió a disminuir, disiparse.

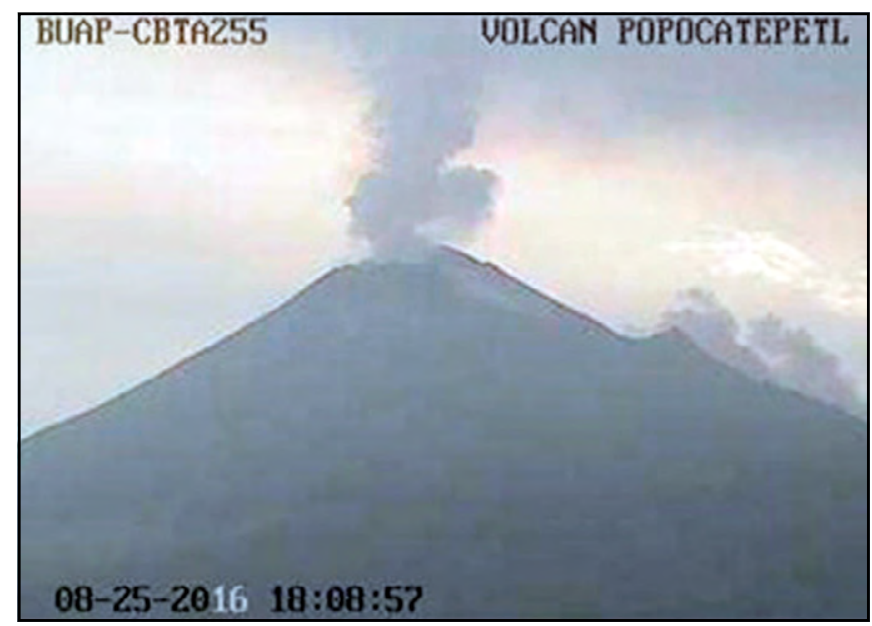

Figura 4. Exhalación de ceniza del día 25 de agosto con una altura de $3,509 \mathrm{~m}$.

Elaboración propia.

Le siguieron emanaciones que alcanzaron más de 3,000 m de altitud, pero la liberación de energía fue mínima, por lo que éstas se disipaban rápidamente y no fue necesario alertar a las poblaciones que colindan con el volcán. Esta actividad se caracterizó por fumarolas de vapor de agua con un registro de al menos 20 exhalaciones a lo largo del día, en la última semana de agosto. Una comparación de la actividad registrada a lo largo del mes se puede apreciar en la figura 5.

Mientras que el mes de septiembre no se presentó mucha actividad, destacada la que ocurrió el día 23, alrededor de las siete de la mañana con una columna de vapor de agua que alcanzó aproximadamente los 2,000 m de altitud (figura 6). El resto del día el volcán siguió exhalando vapor de agua que no alcanzó la

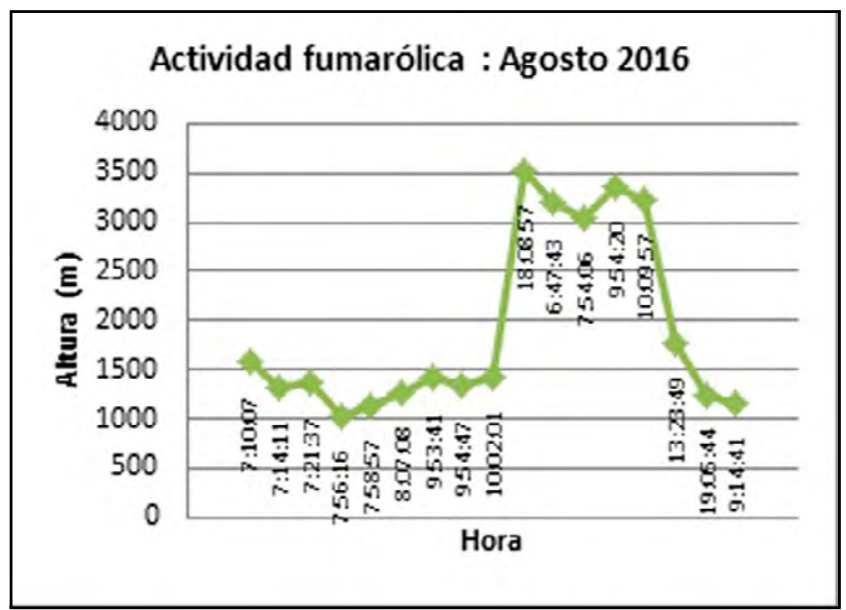

Figura 5. Puntos bajos y mínimos de actividad fumarólica de agosto.

Elaboración propia.

altitud previamente señalada, con una dirección al noroeste y una dispersión de mediana rapidez. Esta actividad se pudo deber al clima que afectó la zona, provocando una nevada en la punta del volcán, con probable filtración de agua que desencadenaría las exhalaciones posteriores.

El resto del mes no se presentaron eventualidades y la actividad disminuyó de manera considerable. El sistema de monitoreo visual no reconoció ninguna exhalación, por tanto, no hubo alertas que pudieran indicar un nuevo evento eruptivo; en la figura 7 se puede apreciar la actividad que se presentó a lo largo del mes de septiembre y con la herramienta de la Universidad de Hawái, MODVOLC, se pudo constatar que no se registró algún punto caliente, con lo que el bimestre finalizó sin actividad significativa.

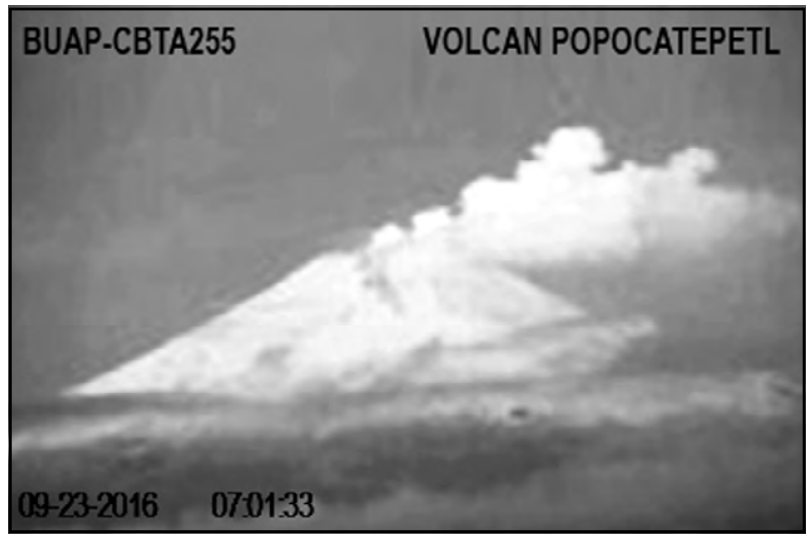

Figura 6. Exhalación de vapor de agua el día 26 de septiembre que alcanzó los 2,000 m.

Elaboración propia. 


\section{InVESTIGACIÓn Y CIERCIA DE LA UחIVERSIDAD AUTÓnOMA DE RGUASCALIENTES}

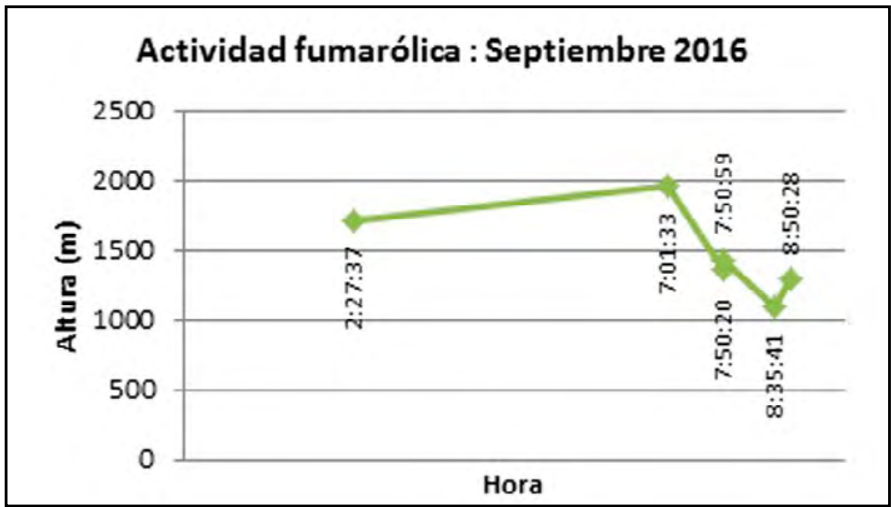

Figura 7. Se muestran los puntos bajos y altos de actividad fumarólica de septiembre.

Elaboración propia.

Bimestre: octubre-noviembre. Fue el bimestre con mayor actividad volcánica, se registraron incandescencia y fumarolas importantes. Si bien el cambio de septiembre a octubre fue paulatino; la segunda semana de octubre, el día 10 aproximadamente a las 8:14 h, comenzó con una exhalación de vapor de agua que alcanzó hasta los 2,927.66 metros a las 9:05 h (figura 8), sin disiparse rápidamente, por lo cual por varios minutos la columna se extendió hacia el norte para después difuminarse al noreste. En la tarde se pudo apreciar incandescencia en el cráter del volcán y en la noche se podía apreciar de nuevo una exhalación pequeña de vapor de agua. De manera similar transcurrieron los días siguientes, con una actividad importante de incandescencia en el cráter y exhalaciones de baja intensidad de vapor de agua.

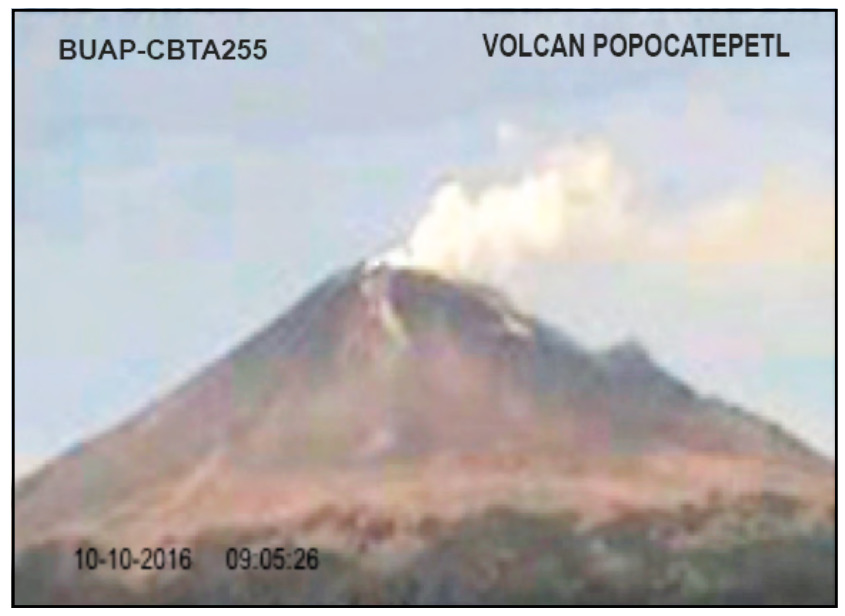

Figura 8. Exhalación de vapor de agua a las 9:05:26 h del día 10 de octubre.

Elaboración propia.
Sin embargo, el 23 del mismo mes el volcán liberó energía con una exhalación de vapor de agua que se elevó hasta los 3,572.46 m (figura 9) y que se mantuvo en una altitud considerable en el transcurso aproximado de tres horas, además de conservar la dirección norte, y a las 11:06 h, que comenzó a disminuir la actividad fumarólica, con dirección al noroeste (figura 10).

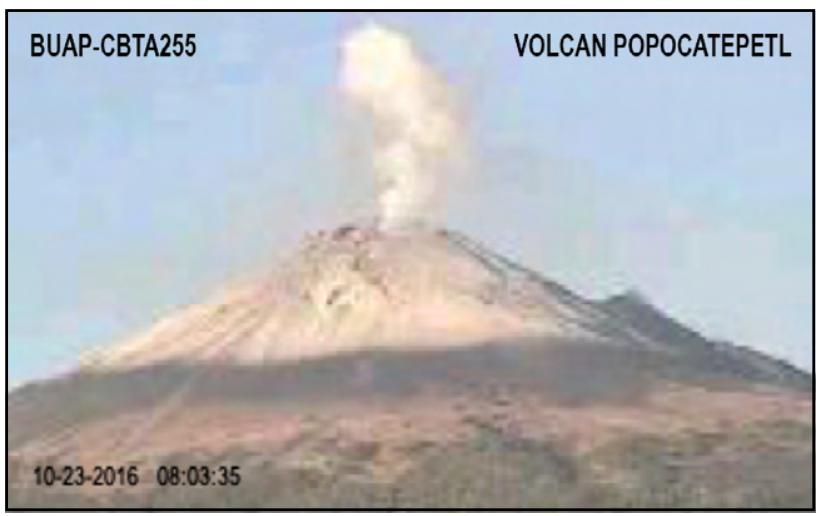

Figura 9. Exhalación de vapor de agua que ocurrió el día 23 de octubre, de $3,572 \mathrm{~m}$.

Elaboración propia.

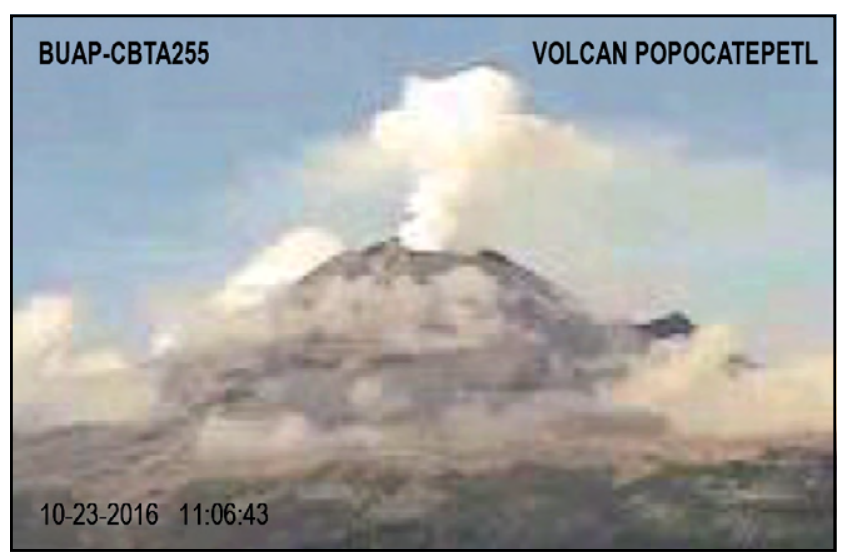

Figura 10. Cambio de dirección al noroeste de la exhalación de vapor de agua del día 23 de octubre.

Elaboración propia.

Ese día en el sistema MODVOLC figuró un punto caliente (figura 11) en el volcán, por lo cual se puede relacionar este evento con la actividad de la cual se tuvo registro.

En el curso del mes la incandescencia seguía constante en el cráter del volcán. Hubo emisión de material, fragmentos basálticos que no eran proyectados muy lejos del cráter, por lo cual no fue necesario realizar evacuaciones de las poblaciones cercanas en el transcurso del mes. El mayor número 


\section{INVESTIGAGIÓก Y CIECEIA DE LA UNIVERSIDAD AUTÓNOMA DE AGUASCALIERTES}

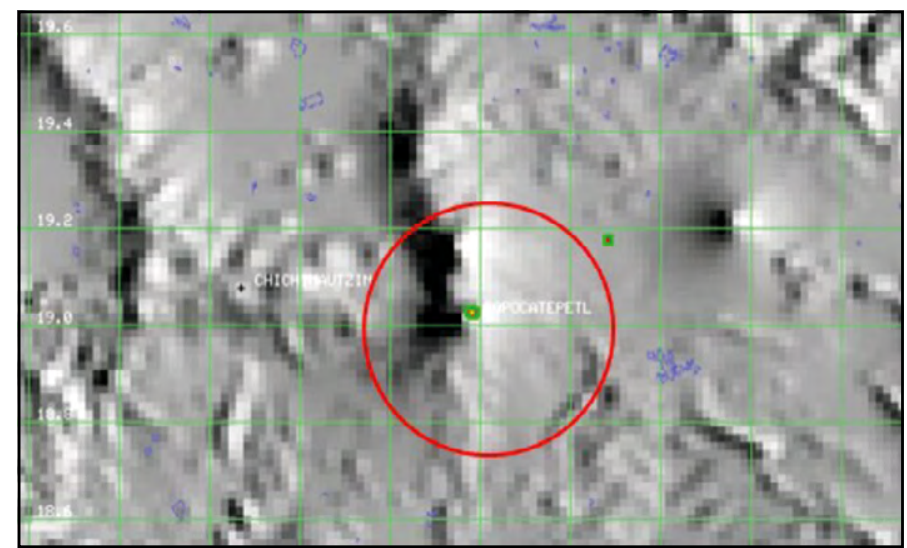

Figura 11. Aparición de un punto caliente en el volcán según la herramienta MODVOLC.

Elaboración propia.

de exhalaciones registradas en la última semana del mes fue de 237 el día 28, la mayoría consistieron en vapor de agua y muy poca ceniza fue arrojada. Sin embargo, el día 30 fue cuando se registraron en un lapso más prolongado de tiempo tremores de baja intensidad aproximadamente por 472 minutos acompañados de incandescencia (figura 12).

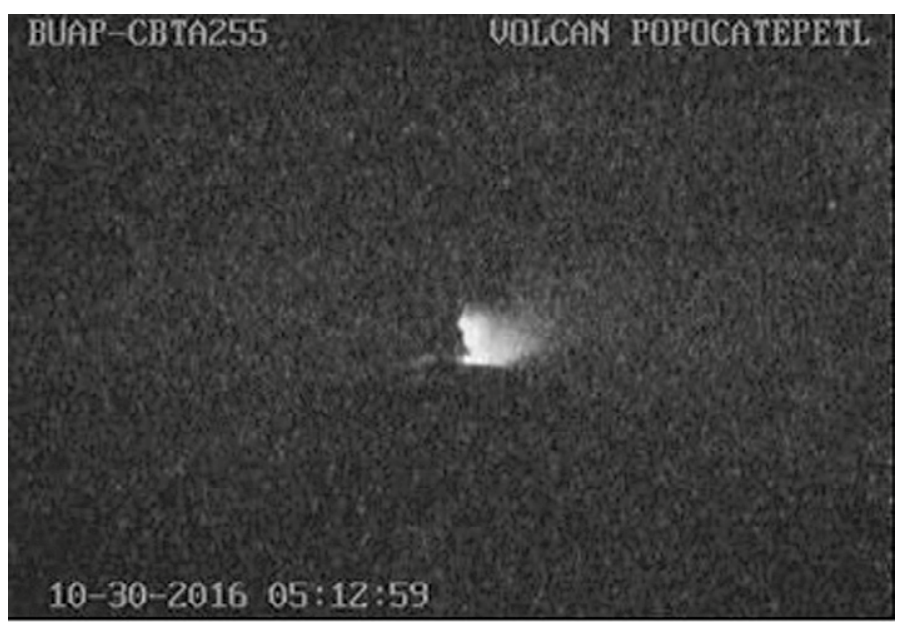

Figura 12. Incandescencia en el cráter del volcán capturada el día 30 de octubre.

Elaboración propia.

La actividad se resumía a los tremores y exhalaciones de baja intensidad para finalizar así el mes de octubre (como se muestra de manera comparativa en la figura 13) y comenzar noviembre con exhalaciones de baja intensidad e incandescencia que se apreciaba a altas horas de la noche y las madrugadas de las primeras dos semanas del mes (figura 14).

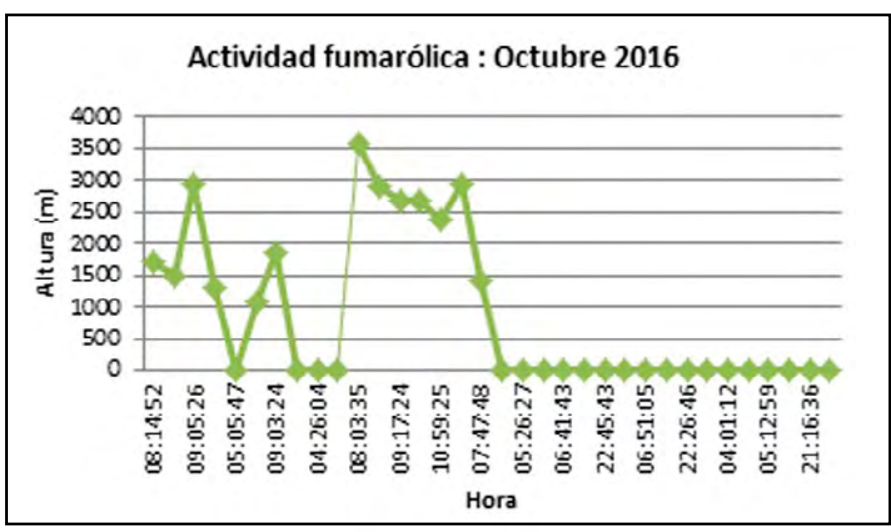

Figura 13. Tabla de dispersión de la actividad fumarólica de octubre.

Elaboración propia.

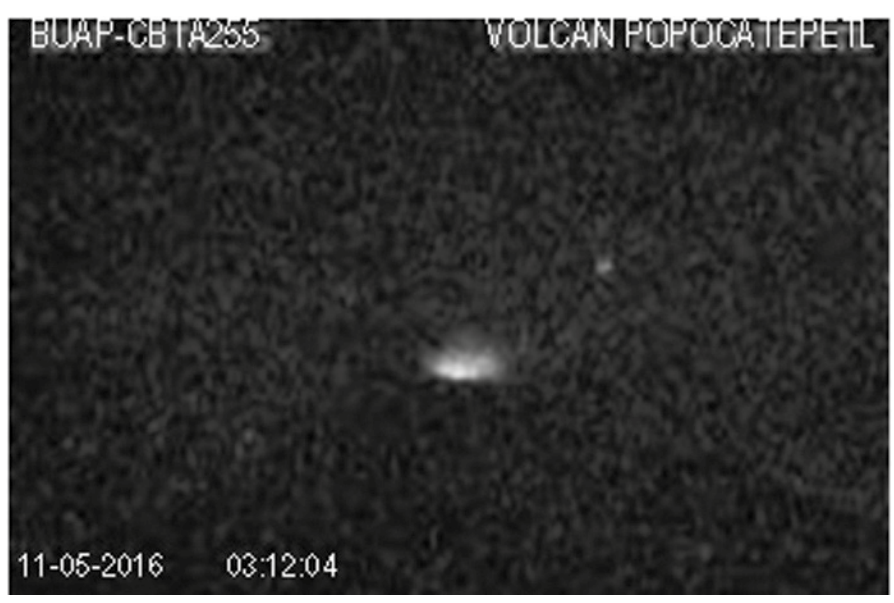

Figura 14. Incandescencia durante la primera semana de noviembre.

Elaboración propia.

En la figura 15 se aprecia lo que el día 24 se registraba según el CENAPRED (2016):

16 eventos vulcano-tectónicos que fueron antecedente al pico máximo de actividad volcánica mostrado el día 25, cuando se tuvo registro de por lo menos 324 exhalaciones antes de una erupción de gases volcánicos y ceniza que se registró a las 9:45 h

La columna se levantó con una altitud máxima de $5 \mathrm{~km}$, la de mayor alcance en el transcurso del año y que tomó dirección al noreste, lo que resultó en caída de ceniza y alarma por material incandescente arrojado a metros del cráter.

El Sistema MODVOLC arrojó una señal de punto caliente en el volcán como se muestra en la figura 16.

El seguimiento dado por el sistema de monitoreo durante los siguientes días concluye que la actividad 


\section{InVESTIGACIÓn Y CIERCIA DE LA UחIVERSIDAD AUTÓnOMA DE RGUASCALIENTES}

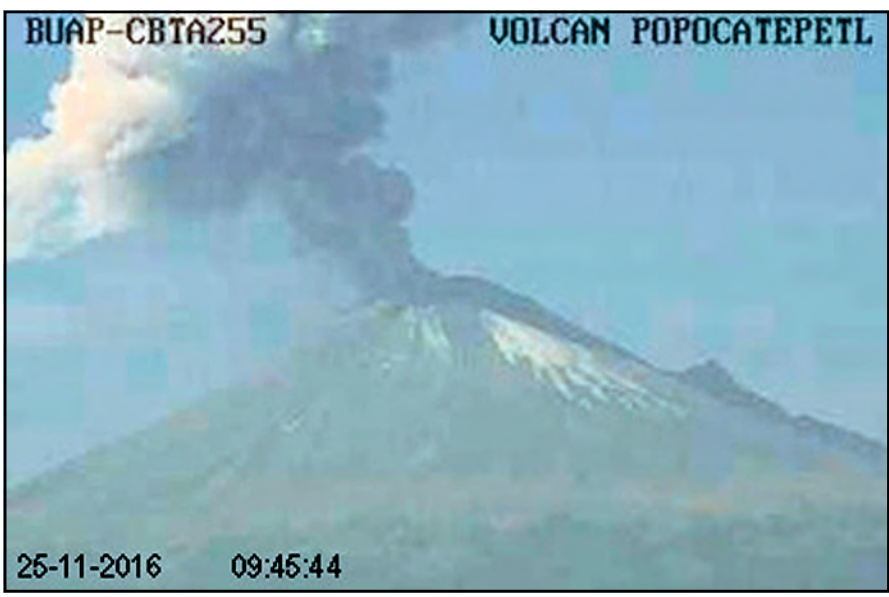

Figura. 15. Exhalación de gases volcánicos y ceniza a las $9: 45 \mathrm{~h}$ del día 25 de noviembre.

Elaboración propia.

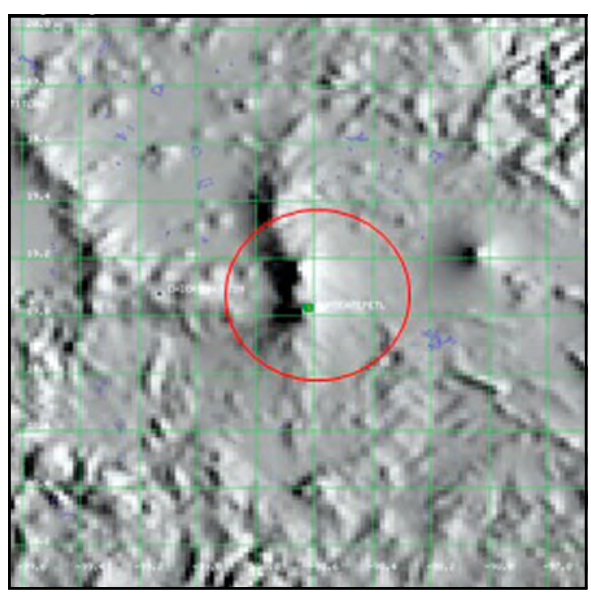

Figura 16. Punto caliente registrado por MODVOLC. Elaboración propia.

regresó a lo que se tenía registrado antes del 25, con incandescencia en el cráter y un máximo de 160 exhalaciones de baja intensidad en su mayoría vapor de agua y gas; el día 29 se volvió a registrar actividad fumarólica considerable, aunque no de la magnitud que se mostró días antes. La columna se elevó hasta los $2 \mathrm{~km}$, sus características fueron vapor de agua y en su mayor parte ceniza. También arrojó material incandescente, aunque a una distancia corta del cráter (figura 17).

Cabe destacar que el punto caliente que detectó el sistema MODVOLC no ha desaparecido y se mantenía hasta el día 5 de febrero de 2017, lo que indica un flujo constante de magma acumulándose, no se deben descartar erupciones de magnitud moderada como las que se observaron el día 25 o 29.

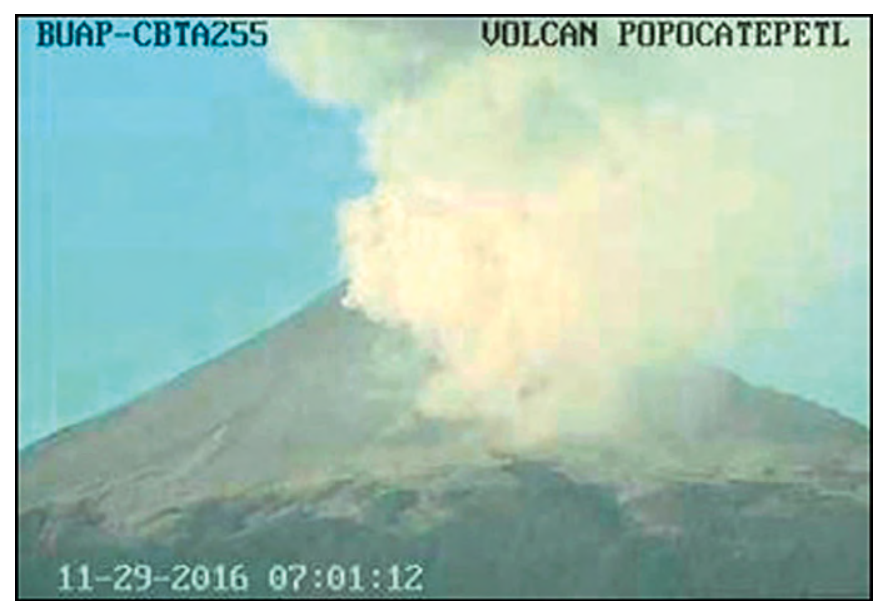

Figura 17. Columna eruptiva de ceniza y vapor de agua del día 29 de noviembre con elevación de hasta $2 \mathrm{~km}$.

Elaboración propia.

En la siguiente gráfica se muestra una comparación de la actividad fumarólica descrita anteriormente, donde se aprecia un flujo importante en la última semana de noviembre (figura 18).

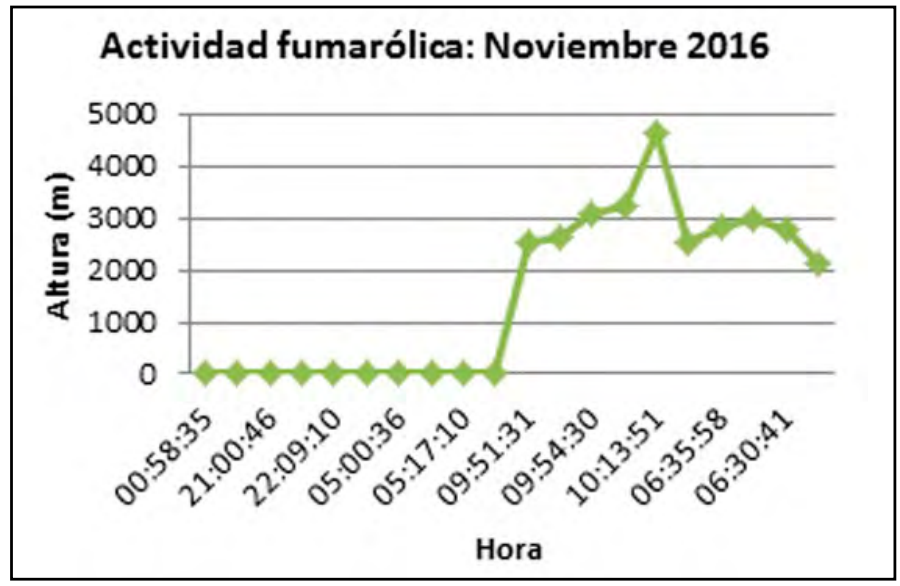

Figura 18. Tabla de dispersión de la actividad fumarólica de noviembre.

Elaboración propia.

De la misma manera se presenta una gráfica para comparar la actividad entre los meses de agosto y noviembre, donde se observan los cambios en la actividad que ha experimentado el volcán Popocatépetl (figura 19).

\section{Análisis del cráter}

El análisis del cráter se llevó acabo por medio de imágenes satelitales rapideye y Landsat 8 , obtenidas mediante las plataformas PLANET y USGS, respectivamente. Se realizó el análisis de los años 2012 hasta 2016 haciendo uso del programa 
IIVESTIGACIÓn Y CIERCIA DE LA UחIVERSIDAD AUTÓnOMH

46 DE RGUASCALIERTES

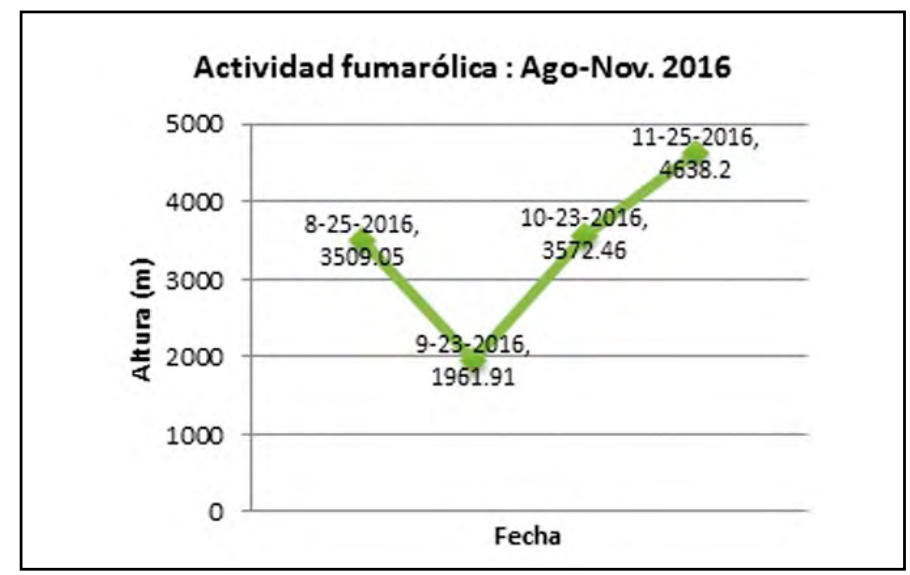

Figura 19. Tabla de dispersión de la actividad fumarólica desde agosto hasta noviembre.

Elaboración propia.

ArcGis para la obtención de perímetro y área del cráter para determinar las modificaciones que han acontecido en estos años.

A pesar de que en 1994 se reinició la actividad volcánica, no fue sino hasta 1996 que el Popocatépetl empezó a sufrir modificaciones en su cráter con la creación y subsecuente destrucción de domos. El registro hasta 2003 fue de aproximadamente 27 domos emplazados en el interior del cráter; sin embargo, esta actividad se redujo para 2005, que duró cuatro años, hasta que en 2009 se volvió a detectar el crecimiento de domos.

Generalmente, a la formación de un domo le anteceden períodos de actividad sismo-volcánica, posteriormente inicia el crecimiento y existen exhalaciones de vapor de agua, gases y cenizas volcánicas. Esto se ha podido observar en el último cuatrimestre del año (2016), donde los sensores han identificado incluso puntos calientes en el volcán y la última exhalación de gran intensidad se llevó a cabo en noviembre.

Año 2012. Se delimitó el cráter para crear un polígono que permitió al programa analizar la información contenida en la imagen y así poder obtener los datos necesarios como el perímetro y área. Desplegando la opción de Identify, el SIG calculó el perímetro de 2,615 metros y el área de $457,305.66 \mathrm{~m}^{2}$.

Año 2013. El resultado fue de $2,365.0 \mathrm{~m}$ de perímetro y de área $433,691.25 \mathrm{~m}^{2}$, se encontró una disminución comparado con 2012 por la formación del domo número 48 que comenzó a formarse de julio a noviembre de ese año.
Año 2014. Para este año por la constante actividad generó una lectura en su perímetro de $2,254.38 \mathrm{~m}$ del cráter, mientras que su área resultó en 432,420.31 m² de acuerdo con el CENAPRED; durante los primeros meses de 2014 se registró la formación y destrucción de dos domos, el número 50 siendo destruido por una explosión que se llevó a cabo el mes de julio de ese año. Sin embargo, para agosto se tuvo la confirmación de la formación del domo número 51 y a partir de ese mes hasta diciembre el monitoreo indicaba las subsecuentes destrucciones hasta la formación del domo 54, con la que finalizó el año.

Año 2015. De acuerdo con las mediciones realizadas por el SIG fue de 2,115.10 m para el perímetro y 415,472.32 $\mathrm{m}^{2}$ para el área, la actividad volcánicatectónica aumentó considerablemente, lo que dio como consecuencia que apenas en febrero de ese año se llevara a cabo la destrucción del domo 54 y la formación del número 55; a partir de ese momento se tuvo registro de 4 domos más y entró 2016 con la formación del número 59.

Año 2016. Los resultados finales del análisis de este año proyectaron un perímetro de 2,376.948 $\mathrm{m}$ y un área de 410,144 m²; estos nuevos datos se deben a la emanación y acumulación de nuevo material y a que en el transcurso del año se registraron emplazamientos de 11 domos, comprendidos en los meses de enero a octubre, ya que en noviembre el CENAPRED dio a conocer la formación del domo número 71. Con el análisis de la actividad fumarólica se puede concluir que la explosión que se llevó a cabo en noviembre fue un detonante para que el cráter sufriera una disminución en su perímetro, que da como resultado lo expuesto en este documento.

\section{DISCUSIÓN}

Se ha visto que la geodinámica del volcán Popocatépetl ha sido constante desde 1994, durante el año 2016 su actividad creció en parámetros fumarólicos y sísmicos, el seguimiento técnico de la geomorfología de la estructura volcánica corroboró el tipo de desarrollo conocido como estratovolcán y su tipo de erupción moderada que tiene la capacidad de permanecer en calma por periodos largos o evolucionar hacia fases más peligrosas. Cabe mencionar que el perímetro del cráter se ve modificado por la actividad del volcán y la acumulación constante de material piroclástico alrededor del cráter, lo que produce que en ocasiones las lecturas del perímetro y cráter varíen. 


\section{IIVESTIGAGIÓn Y CUERCIA DE LA UกIVERSIDAD AUTÓOOOMA DE AGUASCALIERTES}

El cráter del volcán se ha visto deformado desde 1994, pasando de ser un cono casi perfecto de 900 $\mathrm{m}$ de diámetro a $760 \mathrm{~m}$, y de una profundidad que tenía en su labio inferior de $360 \mathrm{~m}$ a casi $155 \mathrm{~m}$. Estos datos calculados hasta diciembre de 2016.

En cuanto a los riesgos por derrumbes y flujos de lodo, podrían darse si una parte del edificio volcánico se colapsara o el único glaciar existente entrara en contacto térmico con el material expulsado, lo cual causaría en un escenario caótico un gran derrumbe cuyo material se desplazaría a una velocidad de $100 \mathrm{~km}$ por hora hasta una distancia de aproximadamente $80 \mathrm{~km}$, destruyendo todo a su paso. Durante los últimos 40,000 años se produjeron dos grandes derrumbes hacia el sur del volcán que cubrieron áreas extensas. "Una erupción grande o un derrumbe gigante estaría acompañado de flujos de lodo e inundaciones de gran alcance" (Marcial, 1996, p. 53).

\section{CONCLUSIONES}

El presente trabajo pretende contribuir al área de geomorfología volcánica en la prevención de alguna actividad mayor del volcán, la importancia de un análisis de estas características se hace relevante con la afirmación de que si la tasa de crecimiento de los domos supera la tasa de destrucción, esto podría tener como consecuencia que el nivel de los domos pudiera superar el del cráter y el resultado sería una amenaza mucho más grande: formación de flujos calientes de bloques, lava y ceniza. Un flujo de lava sería el mejor de los escenarios.

El impacto de los daños depende de la energía acumulada, pero después de todo el análisis fotogramétrico realizado durante 2016 se puede concluir que el volcán Popocatépetl cruza por uno de sus momentos de actividad más intensa. En el último cuatrimestre del año mostró un aumento considerable en la actividad fumarólica que resultó en una de las explosiones más fuertes registradas en los últimos años, con ceniza y diversos gases volcánicos que precedieron la formación del domo número 71 .

Con la ayuda de fotogrametría, software especializado e imágenes satelitales, se cumplieron los objetivos de este trabajo, fue un estudio a fondo, de donde se concluye que la fumarola más grande presenciada en el periodo agosto-noviembre fue la del día 25 del mes de noviembre, con una altura en metros de 4,638.2, de ceniza en su mayor parte y con dirección al noreste; mientras que el análisis del cráter dio como resultado una mayor transformación en el mismo durante 2016, cuando se tomó registro de un mayor número de domos con su subsecuente pero no total destrucción y que alteró en su mayoría los alrededores del cráter.

En una observación adicional, el día 15 de diciembre de 2016 a las 15:00 h, el CENAPRED anunció que el domo número 71 fue destruido por una fuerte explosión seguida de exhalaciones de ceniza y gases volcánicos; sin embargo, las autoridades pertinentes declararon que esto no significaría un cambio en el semáforo del volcán.

Como nota final cabe señalar que en el periodo comprendido desde octubre de 2016 hasta octubre de 2017 la actividad del volcán ha sido muy relevante, en 2017 ha presentado actividad constante de emanación de fragmentos de roca incandescente, ceniza y pequeñas cantidades de lava durante la mayor parte del tiempo.

\section{REFERENCIAS}

- Centro Nacional de Prevención de Desastres. (2001). Las cenizas volcánicas del Popocatépetl y sus efectos para la aeronavegación e infraestructura aeroportuaria [Reporte]. Recuperado de http://www.cenapred.unam.mx/es/ DocumentosPublicos/PDF/partel.pdf

(2012). Resumen de la actividad del volcán Popocatépetl de diciembre de 1994 a mayo de 2001 [Informe]. Recuperado de http://www.cenapred.unam.mx/ es/Instrumentacion/InstVolcanica/MVolcan/Resumen/
informativa]. Recuperada de http://www.cenapred.gob. $\mathrm{mx}: 8080 /$ monitoreoPopocatepetl/

- De la Cruz, S. (1997). Historia eruptiva del volcán Popocatépetl (pp. 20-22). [Ponencia]. CENAPRED.

- Demant, A. (1978). Características del eje neovolcánico transmexicano y sus problemas de interpretación. Revista del Instituto de Geología de la Universidad Nacional Autónoma de México, 2(2), 172-187. 
- Espinasa-Pereña, R. (2014). Historia de la actividad del volcán Popocatépetl. 17 años de erupciones (65 pp.). México: CENAPRED. Recuperado de http://www.cenapred.gob.mx/ es/Publicaciones/archivos/225-HISTORIADELAACTIVIDADDELV OLCNPOPOCATPETL-17AOSDEERUPCIONES.PDF

- Espinasa-Pereña, R., \& Martín-Del Pozzo, A. L. (2006). Morphostratigraphic evolution of Popocatépetl volcano, México. En C. Siebe, J. L. Macías, \& G. J. Aguirre Díaz (Eds.), Neogene-Quaternary continental margin volcanism: A perspective from Mexico: Geological Society of America Special Paper 402 (pp. 101-123). US: Geological Society of America. doi: 10.1130/2006.2402(05)

- Hawaii Institute of Geophysics \& Planetology. (s. f.).MODVOLC, Near- real- time termal monitoring of global hot-spots [Portal electrónico de consulta]. Recuperado el 23 de octubre de 2017, de http://modis.higp.hawaii.edu/cgi-bin/modisnew.cgi

- Macías, J. L. (2005). Geología e historia eruptiva de algunos de los grandes volcanes activos de México. Boletín de la Sociedad Geológica Mexicana, 379-424.

- Marcial, J. (1996). Popocatépetl. Vivir en riesgo. Ciencias, 41 (enero-marzo), 50-55. [En línea]. Recuperado de http:// www.revistaciencias.unam.mx/pt/148-revistas/revistaciencias-41/1225-popocat\%C3\%A9petl-vivir-en-riesgo.html

- Planet. (s. f.). Welcome to the insights economy [Portal electrónico con imágenes en movimiento]. Recuperado de https://www.planet.com/

- United States Geological Survey. (s. f.). EarthExplorer [Portal electrónico de consulta]. Recuperado el 23 de octubre de 2017, de https://earthexplorer.usgs.gov/

\section{OTRAS FUENTES}

\section{Bibliografía}

- Bolla, G. L., Cassano, A. M., \& Franco, J. M. (2009). Estabilidad de barrancas sobre el río Paraná-Modelado por Métodos Numéricos (119 pp.). Paraná: Universidad Tecnológica Nacional.
- Campbell, J. B. (2002). Introduction to remote sensing (pp. 2059). US: CRC Press.

- Cortés-Ramos, J., \& Delgado-Granados, H. (2012). The recent retreat of mexican glaciers on Citlaltépetl Volcano detected using ASTER data. The Cryosphere Discussions, 6, 3149-3176.

- Dóniz, F. J. (2002). El volcanismo basáltico de la dorsal de Pedro Gil en la isla de Tenerife. Papeles de Geografía, 35, 101-114.

- García, F., Ramos, E., \& Domínguez, R. (1996). Posible flujo de lodo en el costado oriente del volcán Popocatépetl. En Volcán Popocatépetl. Estudios realizados durante la crisis de 1994-1995 (pp. 109-119). México: Sistema Nacional de Protección Civil-Centro Nacional de Prevención de DesastresUniversidad Nacional Autónoma de México.

- Ontiveros, G., Delgado, H., \& Cortés, J. (sometido a dictamen para publicación). The surface energy balance of Glaciar Norte on Citlaltépetl volcano, Mexico during 2006-2009. Geofísica Internacional.

- Palacios, D., \& Vázquez-Selem, L. (1996). Geomorphic effects of the retreat of Jamapa glacier, Pico de Orizaba volcano (Mexico). Geografiska Annaler: Series A, Physical Geography, 78, 19-34.

- Ramos-Aguilar, R., Máximo-Romero, P., González-Castelán, Y. J., \& Montiel-Peralta, B. A. (2005). Monitoreo y vigilancia del volcán Citlaltépetl o Pico de Orizaba (análisis geomorfológico). Revista Geofísica, 61, 33-45.

- Ramos-Aguilar, R., Máximo-Romero, P., Montiel-Peralta, B. A., González-Castelán, Y. J., \& Rodríguez-Marcos, A. (2008). Análisis fotogramétrico del volcán Citlaltépetl. Revista Cartográfica, 84, 105-116.

- Ramos-Aguilar, R., Máximo-Romero, P., Soto-Cruz, B. S., Alcántara-Iniesta, S., \& Vázquez-García, M. C. (2014). Análisis geoestadístico de las barrancas Colorada y Quimichule del volcán Popocatépetl (México) como aporte a la prevención de desastres naturales. Investigaciones Geográficas, 47, 67-82.

- Schenk, T. (2002). Fotogrametría digital (Geomática Vol. I). España: Marcombo-ICC. 